\title{
Uncultivated thermophiles: Current status and spotlight on
}

\section{'Aigarchaeota'}

11

12 Brian P. Hedlund ${ }^{1,2^{*}}$, Senthil K. Murugapiran ${ }^{1}$, Timothy W. Alba ${ }^{1}$, Asaf Levy ${ }^{3}$, Jeremy

15 1. School of Life Sciences, University of Nevada Las Vegas, Las Vegas, NV 89154, USA

2. Nevada Institute of Personalized Medicine, University of Nevada, Las Vegas, Nevada, 89154, USA

4. Department of Biology, California State University, San Bernardino, California, 92407, USA

\section{3 *Correspondence:}

24 Brian P. Hedlund, School of Life Sciences, University of Nevada, Las Vegas, 4505

25 Maryland Parkway, Las Vegas, NV 89154-4004, USA.

26 Tel.: +1 (702) 895-0809

27 E-mail: brian.hedlund@unlv.edu 


\section{HIGHLIGHTS}

30 - Independent analyses show novel taxa and coding sequences are highly abundant

31 in geothermal systems.

32 - Candidate taxa include 'Aigarchaeota', 'Korarchaeota', 'Calescamantes', and 33 'Fervidibacteria'.

34 - Genomic exploration provides a window into the biology of uncultivated 35 microbes.

36 - 'Aigarchaeota' is a diverse, globally-distributed group of obligate thermophiles.

\section{ABSTRACT}

39 Meta-analysis of cultivation-independent sequence data shows that geothermal systems

40 host an abundance of novel organisms, representing a vast unexplored phylogenetic and

41 functional diversity among yet-uncultivated thermophiles. A number of thermophiles

42 have recently been interrogated using metagenomic and/or single-cell genomic

43 approaches, including members of taxonomic groups that inhabit both thermal and non-

44 thermal environments, such as 'Acetothermia' (OP1) and 'Atribacteria' (OP9/JS1), as well

45 as the exclusively thermophilic lineages 'Korarchaeota', 'Calescamantes' (EM19),

46 'Fervidibacteria' (OctSpA1-106), and 'Aigarchaeota' (HWCG-I). The 'Aigarchaeota', a

47 sister lineage to the Thaumarchaeota, likely includes both hyperthermophiles and 48 moderate thermophiles. They inhabit terrestrial, marine, and subsurface thermal

49 environments and comprise at least nine genus-level lineages, several of which are 50 globally distributed. 


\section{INTRODUCTION}

52 Geothermal systems hosting thermophiles (optimum growth $45-80 \quad{ }^{\circ} \mathrm{C}$ ) and

53 hyperthermophiles $\left(>80{ }^{\circ} \mathrm{C}\right)$ were some of the first environments to be explored by

54 cultivation-independent approaches using 16S rRNAs and 16S rRNA gene amplicons [1,

55 2]. These studies and many others revealed a vast diversity that filled in and expanded the

56 tree of life, with yet-uncultivated organisms spanning the phylum to species level.

57 Cultivation-independent investigations of Obsidian Pool in Yellowstone National Park

58 were particularly ground-breaking, revealing deeply branching Archaea, including

59 'Korarchaeota' [3, 4], and twelve novel lineages of Bacteria, provisionally named OP1-

60 OP12 [5]. Many of these were subsequently shown to also inhabit non-thermal

61 environments and have come into focus in a variety of habitats [e.g., 6, 7, 8]. Over the

62 last ten years, a few thermophilic members of these groups and others have been isolated

63 and described as axenic cultures [e.g., 9, 10, 11, 12, 13]; however, most of the diversity

64 within them remains to be explored. Recent advancements in metagenomics and single-

65 cell genomics have provided access to the genomes of yet-uncultivated thermophiles,

66 enabling insight into their evolution, cell biology, and possible metabolic and ecological

67 functions. Continued genomic exploration of these enigmatic organisms, along with

68 experiments to test their functions in situ and cultivate them in the laboratory, will be an

69 exciting frontier in biology for decades to come.

71 EXTENT OF YET-UNCULTIVATED THERMOPHILE DIVERSITY

72 Currently there are over 4.3 million 16S rRNA gene sequences in public databases (14).

73 Despite exponential increases in the number of entries per year, the accumulation of new 
74 operational taxonomic units at all levels is approaching an asymptote, with total bacterial

75 species richness predicted to be $\sim 4 \times 10^{5}[\bullet \bullet 15]$. At present, it is difficult to estimate the

76 taxonomic richness of thermophiles and hyperthermophiles, although well-established

77 negative correlations between microbial diversity and temperature $[\bullet 16, \bullet 17]$ suggest it

78 may be a small fraction of the total taxonomic richness. Nevertheless, with very few

79 species of thermophiles and hyperthermophiles formally described $(<1,000$, estimated

80 from $\sim 12,000$ total species on the List of Prokaryotic Names with standing in

81 Nomenclature [18]), the vast majority remains to be carefully studied. More intriguingly,

82 many deep branches of thermophiles also remain poorly represented, or unrepresented by

83 axenic cultures. Estimates of the total number of phyla of Bacteria and Archaea

84 commonly range from 50 to $100[19,20]$; however, a conservative, unbiased approach

85 recently estimated $\sim 1,600$ bacterial lineages equivalent to the existing bacterial phyla

$86[\bullet \bullet 15]$. As with species, the number of phylum-level lineages containing some or many

87 thermophiles is currently difficult to determine.

89 Cultivation-independent studies of geothermal systems provide a window to assess the

90 abundance and distribution of yet-uncultivated thermophile diversity (Figure 1; Table S1;

91 Table S2). The most comprehensive view currently available is gained by meta-analysis

92 of $16 \mathrm{~S}$ rRNA gene amplicon data. Parallel analysis of data from eight regions,

93 comprising 372 samples from terrestrial geothermal systems $[\bullet 16, \bullet 17,21-27]$ suggests a

94 high abundance of uncultivated high-level taxa in geothermal systems globally, including

95 phyla $(\bar{x}=16.8 \%)$, classes $(\bar{x}=34.0 \%)$, orders $(\bar{x}=42.1 \%)$, and families $(\bar{x}=46.9 \%)$. Most

96 regions show a somewhat even distribution of uncultivated taxa among samples; 
97 however, an exception is Tengchong, China, in which the Rehai Geothermal Field

98 springs contain a very low apparent abundance of uncultivated organisms and the Ruidian

99 (Dientan) springs contain a very high abundance of uncultivated organisms $(24,27)$.

100 Hotspots of uncharacterized biodiversity like the Ruidian springs may be obscured in

101 other regions by greater sampling effort or different sampling strategies.

102

103 Examining metagenomes from geothermal systems in the Integrated Microbial Genomes-

104 Microbiomes $(\mathrm{IMG}-\mathrm{M})$ database $(\bullet 28,29)$ provides another view of the extent of yet-

105 uncultivated thermophile biodiversity. Analysis of proteins extracted from assemblies for

10662 datasets reveals a very broad range of apparent abundance of unexplored genomic

107 diversity, with $10 \%$ to $92 \%$ of predicted coding sequences taxonomically unassigned at

$10860 \%$ amino acid identity $(\bar{x}=55.1 \%, n=62)$ (Table S2; calculated using UCHIME in IMG-

$109 \mathrm{M}$ [29]). This level of amino acid identity is comparable with the family level since

110 bacterial genus boundaries correspond to $\sim 65 \%$ average amino acid identity (AAI)[30];

111 however, unassigned genes may also represent elements of the accessory genome

112 residing within known taxa. Although these springs span a wide range of temperature

$113\left(50-90{ }^{\circ} \mathrm{C}\right)$ and $\mathrm{pH}(2.1-9.3)$, no relationship between the percent of taxonomically

114 unassigned sequences and either temperature $\left(r^{2}=0.07\right)$ or $\mathrm{pH}\left(r^{2}=0.02\right)$ is evident (Table

115 S2). Lastly, 16S rRNA genes extracted from these datasets represent a source of

116 information, although read depth, which is necessary for abundance estimation, is only

117 available for a subset of metagenomes. This approach also shows a wide variation in the

118 abundance of yet-uncultivated microorganisms, with 0 to $82 \%$ of $16 \mathrm{~S}$ rRNA gene

119 sequences being taxonomically unassigned at the phylum level $(\bar{x}=32.1 \%, n=24)$ with a 
120 higher abundance of unassigned sequences at the class $(\bar{x}=37.8 \%)$, order $(\bar{x}=40.1 \%)$, and

121 family ( $\bar{x}=44.1 \%$ ) levels (Table S2; assigned using Greengenes). Despite many caveats

122 deriving from differential DNA extraction efficiency, primer bias, uneven

123 taxonomic/phylogenetic structure, and differences in phylogenetic resolution among

124 different regions of the 16S rRNA gene [e.g., $\bullet 15$ ], these data suggest that uncultivated

125 taxa are abundant in most geothermal systems.

127 [INSERT FIGURE 1 HERE]

129 PROGRESS ON THERMOPHILE METAGENOMICS AND SINGLE-CELL

\section{GENOMICS}

131 A few studies have explicitly targeted yet-uncultivated, deep lineages of thermophiles by

132 using metagenomics or single-cell genomics approaches in geothermal environments.

133 Studies of a thermal spring in a Japanese gold mine $\left(70^{\circ} \mathrm{C}, \mathrm{pH} 5.1\right)$ involved screening a

134 fosmid library for 16S rRNA genes of interest, followed by both targeted and random

135 fosmid clone sequencing, leading to a complete genomic assembly for 'Candidatus

136 Caldiarchaeum subterraneum' a member of a deeply branching archaeal group, Hot Water

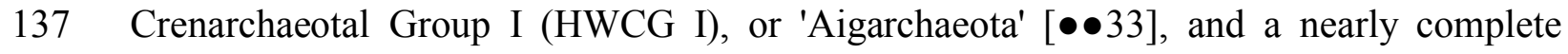

138 genomic assembly for 'Candidatus Acetothermum autotrophicum', belonging to candidate

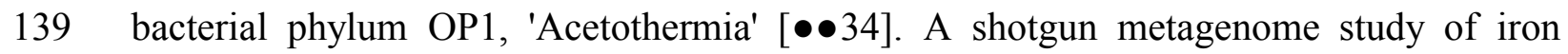

140 oxide mats in One Hundred Springs Plain Spring $\left(60-78{ }^{\circ} \mathrm{C}\right.$, pH 3.5) in Norris Geyser

141 Basin, Yellowstone, yielded a near-complete consensus genome from a deeply branching

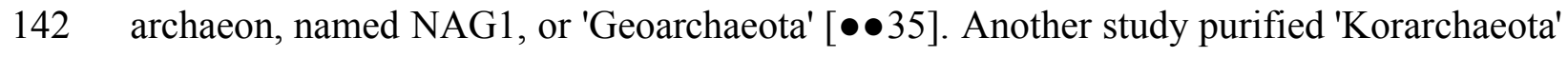


143 cells from an enrichment culture $\left(85^{\circ} \mathrm{C}, \mathrm{pH}\right.$ 6.5; Obsidian Pool) by SDS treatment

144 followed by filtration $(0.45 \mu \mathrm{m})$, enabling sequencing and assembly of a complete

145 genome for 'Candidatus Korarchaeum cryptofilum' [••36]. In the U.S. Great Basin, one

146 study combined single-cell genome sequencing of 15 single cells sorted and amplified

147 using an optofluidic approach from Little Hot Creek, California $\left(80^{\circ} \mathrm{C}, \mathrm{pH} \sim 7\right)$ and

148 shotgun metagenomic sequencing of a cellulolytic enrichment from Great Boiling Spring,

149 Nevada $\left(77^{\circ} \mathrm{C}, \mathrm{pH} \sim 7\right)[\bullet \bullet 37]$, yielding two fragmented but nearly complete genome

150 assemblies for members of candidate bacterial phylum OP9 'Atribacteria', provisionally

151 named 'Candidatus Caldatribacterium californiense' and 'Ca. Caldatribacterium

152 saccharofermentans'. Samples from Great Basin springs were also part of the largest

153 single-cell genomics study to date, the Genomic Exploration of Bacteria and Archaea-

154 Microbial Dark Matter (GEBA-MDM) project, which used fluorescence activated cell

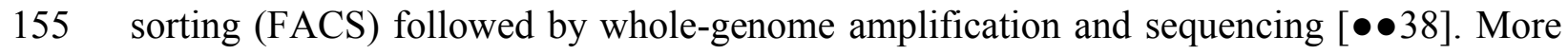

156 than 30 single cell genomes were obtained from natural sediments in Great Boiling

157 Spring, including assemblies ranging from $50-95 \%$ estimated genome coverage for two

158 lineages, EM19 ('Calescamantes'; 'Candidatus Calescibacterium nevadense'; 10 single-

159 amplified genomes (SAGs)), and OctSpA1-106 ('Fervidibacteria', 'Candidatus

160 Fervidibacter sacchari'; 5 SAGs), along with large assemblies for several unnamed

161 'Aigarchaeota' species (14 SAGs) and smaller datasets for additional deep lineages.

162

163 In aggregate, these studies and others [e.g., 39, 40] have significantly expanded the 164 genomic coverage of thermophilic Bacteria and Archaea. The major metabolic features 165 of these organisms seem to be diverse (Figure 2). Based on genome-enabled predictions, 
166 the lineages described above potentially encode systems for autotrophy ('Acetothermum',

167 'Caldatribacterium'), aerobic respiration ('Acetothermum', 'Caldatribacterium',

168 'Calescibacterium', 'Fervidibacterium'), and various forms of anaerobic respiration

169 ('Acetothermum', 'Caldatribacterium', 'Calescibacterium', 'Fervidibacter').

170 'Caldatribacterium' and 'Korarchaeum' are predicted to be obligate fermenters. Most of

171 these representative organisms are rod-shaped or filamentous, based on either direct

172 observation $[\bullet \bullet 36, \bullet \bullet 37]$ or the presence of genes for MreB or crenactin, and all of the

173 bacteria are probably diderm (i.e. Gram negative), based on genes encoding components

174 for outer membrane synthesis and transport [41]. The Archaea are presumed to be

175 monoderm. None of these lineages appear to be symbionts, based on genome size and

176 predicted biosynthetic potential, distinguishing these organisms from a multitude of deep

177 lineages of Bacteria and Archaea that have reduced genome sizes $(<1.3 \mathrm{Mbp})$ and

178 predicted symbiotic lifestyles [e.g., 20, • 38, 42-49].

180 It is noteworthy that the provisional taxonomy of these organisms is uncertain on several

181 grounds, including: the requirement in microbial systematics for well-described axenic

182 cultures; current limitations on higher-order taxonomy, which does not cover

183 classifications above class; and disagreements within the scientific community about

184 these unofficial designations and their applications to various lineages [e.g., $\bullet \bullet 50,51$ -

185 54]. Some members of the systematics community have recently encouraged discussion

186 to emend Candidatus status to better take advantage of advancements in environmental

187 genomics [55][56]; however, no recent changes have been ratified by the International

188 Committee on the Systematics of Bacteria and Archaea. 
190 Metagenomic datasets provide a means to assess the distribution and abundance of yet-

191 uncultivated taxa for which reference genomes exist. We used a conservative approach of

$192>70 \%$ nucleotide identity and $>100$ bp long hits to recruit reads from 59 metagenomes

193 from terrestrial and marine geothermal systems $[\bullet 28,57-60]$ to seven reference genomes

$194[\bullet \bullet 37, \bullet \bullet 36,49, \bullet \bullet 38, \bullet \bullet 34]$. This analysis roughly targets genus-level recruitment

195 [30] and suggests that members of the 'Aigarchaeota' ('Ca. Caldiarchaeum'),

196 'Korarchaeota' ('Ca. Korarchaeum'), 'Nanoarchaeota' ('Ca. Nanobsidianus'),

197 'Acetothermia' (' $\mathrm{Ca}$. Acetothermum'), 'Atribacteria' ('Ca. Caldatribacterium'),

198 'Calescamantes' ('Ca. Calescibacterium'), and 'Fervidibacteria' ('Ca. Fervidibacter') are

199 present in a majority of geothermal systems (Figure 2; Table S3). "Ca. Caldatribacterium'

200 and "Ca. Calescibacterium' were particularly widespread, being detected in $>80 \%$ of

201 metagenomes, including metagenomes from all terrestrial systems analyzed, as well as

202 marine hydrothermal systems. Close relatives of 'Candidatus Nanobsidiaunus stetteri'

203 were particularly widespread in Yellowstone metagenomes, with $>0.1 \%$ estimated

204 abundance in $29 \%$ of Yellowstone metagenomes, all of which are from acid sulfate

205 systems hosting the probable host, Sulfolobales [49]. Some springs hosted many of these

206 candidate taxa, including Great Boiling Spring and Little Hot Creek (Great Basin),

207 Octopus Spring, OSP Spring, and Beowulf Spring (Yellowstone), as well as Gongxiaoshe

208 and Gumingquan (Tengchong)(Figure 2). These candidate taxa were poorly represented

209 in marine hydrothermal samples; however, this is not surprising since the fragment

210 recruitment strategy was stringent. This high stringency also explains the low recruitment 
211 of candidate phyla in springs in which they are known to be abundant and diverse (e.g.,

$212 \bullet 16)$

213

214 [INSERT FIGURE 2 HERE]

216 'AIGARCHAEOTA': GENOMIC INSIGHTS, DIVERSITY, AND DISTRIBUTION

217 One deep lineage that has received considerable attention in the literature, but is still

218 poorly studied is the HWCG I group, or 'Aigarchaeota'. The 'Aigarchaeota' was first

219 highlighted as part of an investigation of a mildly acidic spring within a Japanese gold

220 mine as a single fosmid clone and later an entire composite genome of 'Candidatus

221 Caldiarchaeum subterraneum' $[\bullet \bullet 33]$. Analysis of predicted features led the authors to

222 suggest that this organism may couple hydrogen or carbon monoxide oxidation to aerobic

223 or anaerobic respiration using nitrate or nitrite as electron acceptors. However, the

224 hydrogenases in "Ca. Caldiarchaeum subterraneum" belong to Group 3B and Group 4

225 NiFe hydrogenases [61], characterized members of which regulate redox homeostasis

226 rather than hydrogenotrophy. ' $\mathrm{Ca}$. Caldiarchaeum subterraneum' may be autotrophic via

227 the dicarboxylate/4-hydroxybutyrate pathway, but lacks a canonical 4-hydroxybutyryl-

228 CoA dehydratase. Preliminary analysis of single-cell genomes of several 'Aigarchaeota'

229 lineages from Great Boiling Spring has yielded additional insights, including potential

230 capacity for heterotrophic utilization of proteins and sugars and, in some cases, anaerobic

231 respiration using sulfite or nitrous oxide $[\bullet \bullet 38]$. A more detailed interpretation and

232 comparative analysis of these and other genomes from a diversity of 'Aigarchaeota' 
233 lineages and thermal environments is necessary to reveal potential core traits and the

234 extent of metabolic plasticity within the 'Aigarchaeota'.

235

236 Phylogenomic and comparative genomic studies have consistently revealed a deep

237 relationship between Thaumarchaeota, 'Aigarchaeota', Crenarchaeota, and 'Korarchaeota'

238 in the 'TACK superphylum' $[\bullet \bullet 38,52,62,63]$, yet there is some uncertainty about

239 whether 'Aigarchaeota' should be considered an independent phylum or a deep branch

240 within the Thaumarchaeota $[50,51,52]$. This uncertainty is symptomatic of unrest among

241 microbiologists seeking consensus on guidelines for higher-order taxonomy, particularly

242 Archaea [51, 54]. The 16S rRNA gene identity between 'Aigarchaeota' and

243 Thaumarchaeota $(77-79 \%)$ is lower than the median sequence identity delimiting

244 bacterial phyla $(83.68 \%[\bullet \bullet 15])$ and close to the minimum distance between bacterial

245 phyla $(77.43 \%[\bullet \bullet 15])$, but has been reported to be similar to that delimiting

246 euryarchaeal orders $[\bullet \bullet 50]$. Regardless, it is clear that the cell biology of 'Aigarchaeota'

247 shares many features with Thaumarchaeota $[\bullet \bullet 50,64]$, although their ecology appears to

248 be distinct. The evolution of metabolically specialized Thaumarchaeota from an

249 apparently more flexible 'Aigarchaeota' ancestor $[\bullet \bullet 33, \bullet \bullet 38]$ may be one of many

250 examples of streamlining in archaeal evolution [63].

251

252 The 'Aigarchaeota' are phylogenetically diverse and inhabit a wide array of thermal 253 ecosystems, including terrestrial and marine geothermal systems, subsurface aquifers, and

254 mine fracture waters (Figure 3; Figure 4; Table S4). Clustering and phylogenetic analysis

255 of 'Aigarchaeota' 16S rRNA gene sequences from 16S rRNA gene surveys, single-cell 
256 genomes, and metagenomes, shows at least nine genus-level groups $(<95 \% 16 \mathrm{~S}$ rRNA

257 gene identity $[\bullet \bullet 15]$ ), although some are not strongly supported and should be

258 reevaluated as additional sequences become available (Figure 3; Table S5; Table S6). All

259 groups are found in terrestrial geothermal systems, including deeply branching

260 'Aigarchaeota', suggesting a terrestrial origin (Figure 4). A few 'Aigarchaeota' 16S rRNA

261 gene sequences have been recovered from moderate- or cold-temperature samples;

262 however, the vast majority are from high-temperature environments and all have a $16 \mathrm{~S}$

263 rRNA gene $\mathrm{G}+\mathrm{C}$ content consistent with a thermophilic or hyperthermophilic lifestyle,

264 with calculated optimal growth temperatures of $40.8-101.9{ }^{\circ} \mathrm{C}\left(\bar{x}=78.4{ }^{\circ} \mathrm{C}, n=357\right)($ Table

265 S3)[65]. A general trend toward lower $16 \mathrm{~S}$ rRNA gene $\mathrm{G}+\mathrm{C}$ content in newer and

266 longer branches suggests a high-temperature origin, with niche invasion to lower

267 temperature systems. 'Aigarchaeota' are predominantly found in habitats with

268 circumneutral pH. The U.S. Great Basin appears to be somewhat of a hotspot for

269 'Aigarchaeota' diversity and abundance, with several 'Aigarchaeota' lineages prominent in

270 Great Boiling Spring [•16, 66], Mud Hot Springs [66], Grass Valley Spring [67], Little

271 Hot Creek [68], and an aquifer at the Nevada National Security Test Site. However,

272 sampling is currently highly biased and the full extent of 'Aigarchaeota' diversity is yet to

273 be uncovered.

274

275 [INSERT FIGURE 3 AND FIGURE 4 HERE]

276

277 OUTLOOK 
278 Both taxonomic and genomic diversity are poorly represented by thermophile laboratory

279 cultures. Understanding thermophile diversity and ecology necessitates a polyphasic

280 approach to biodiversity exploration, including microbial cultivation and characterization,

281 cultivation-independent genomic exploration, and in situ activity measurements.

282 Exploration of thermophile biodiversity will remain an exciting and important field for

283 decades to come.

\section{ACKNOWLEDGEMENTS}

286 This work was supported by NASA Exobiology grant EXO-NNX11AR78G; U.S.

287 National Science Foundation grant OISE 0968421; U.S. Department of Energy (DOE)

288 grant DE-EE-0000716; and the U.S. Department of Energy Joint Genome Institute (CSP-

289 182), a DOE Office of Science User Facility, supported under Contract No. DE-AC02-

290 05CH11231. B.P.H. acknowledges generous support from Greg Fullmer through the

291 UNLV Foundation. T.W.A. was supported by the Richard and Beverly Hermsen

292 Fellowship. G.B.G. was supported by the Robert E. McNair Foundation and NSF DBI -

293 1358896. We acknowledge Steve Quake, Paul Blainey, Jad Kanbar, and Iwijn De

294 Vlaminck for collaboration with single-cell genomics and metagenomics and Hailiang

295 Dong and Brandon Briggs for collaboration with metagenomics. William Inskeep and

296 Jake Beam provided an 'Aigarchaeota' 16S rRNA gene sequence from Octopus Spring.

297 Duane Moser and Scott Hamilton-Brehm provided 16S rRNA gene sequences from the

298 Nevada National Security Site (NNSS). Scott Miller, Ken Jones, Eric Boyd, and Trinity

299 Hamilton kindly provided raw 16S rRNA gene pyrotag reads. Fengping Wang, William

300 Brazelton, and Matthew Schrenk kindly provided metagenomic datasets. 
REFERENCES

$304 \bullet \bullet$ of outstanding interest

1. Stahl DA, Lane DJ, Olsen GJ, Pace NR: Analysis of hydrothermal ventassociated symbionts by ribosomal RNA sequences. Science 1984, 224:409411.

2. Reysenbach AL, Wickham GS, Pace NR: Phylogenetic analysis of the hyperthermophilic pink filament community in Octopus Spring, Yellowstone National Park. Appl Environ Microbiol 1994, 60:2113-2119.

3. Barns SM, Fundyga RE, Jeffries MW, Pace NR: Remarkable archaeal diversity detected in a Yellowstone National Park hot spring environment. Proc Natl Acad Sci U S A 1994, 91:1609-1613.

4. Barns SM, Delwiche CF, Palmer JD, Pace NR: Perspectives on archaeal diversity, thermophily and monophyly from environmental rRNA sequences. Proc Natl Acad Sci USA 1996, 93:9188-9193.

5. Hugenholtz P, Pitulle C, Hershberger KL, Pace NR: Novel division level bacterial diversity in a Yellowstone hot spring. $J$ Bacteriol 1998, 180:366-376.

6. Farag IF, Davis JP, Youssef NH, Elshahed MS: Global patterns of abundance, diversity and community structure of the Aminicenantes (candidate phylum OP8). PLoS One 2014, 9:e92139. 
7. Glöckner J, Kube M, Shrestha PM, Weber M, Glöckner FO, Reinhardt R, Liesack W: Phylogenetic diversity and metagenomics of candidate division OP3. Environ Microbiol 2010, 12:1218-1229.

8. Lee KC, Herbold CW, Dunfield PF, Morgan XC, McDonald IR, Stott MB: Phylogenetic delineation of the novel phylum Armatimonadetes (former candidate division OP10) and definition of two novel candidate divisions. Appl Environ Microbiol 2013, 79:2484-2487.

9. Dodsworth JA, Gevorkian J, Despujos F, Cole JK, Murugapiran SK, Ming H, Li WJ, Zhang G, Dohnalkova A, Hedlund BP. Thermoflexus hugenholtzii gen. nov., sp. nov., a thermophilic, microaerophilic, filamentous bacterium representing a novel class in the Chloroflexi, Thermoflexia classis nov., and description of Thermoflexaceae fam. nov. and Thermoflexales ord. nov. Int J Syst Evol Microbiol. 2014, 64:2119-2127.

10. Iino T, Mori K, Uchino Y, Nakagawa T, Harayama S, Suzuki K: Ignavibacterium album gen. nov., sp. nov., a moderately thermophilic anaerobic bacterium isolated from microbial mats at a terrestrial hot spring and proposal of Ignavibacteria classis nov., for a novel lineage at the periphery of green sulfur bacteria. Int J Syst Evol Microbiol 2010, 60:1376-1382.

11. Lee KC, Dunfield PF, Morgan XC, Crowe MA, Houghton KM, Vyssotski M, Ryan JL, Lagutin K, McDonald IR, Stott MB: Chthonomonas calidirosea gen. nov., sp. nov., an aerobic, pigmented, thermophilic microorganism of a novel bacterial class, Chthonomonadetes classis nov., of the newly described phylum Armatimonadetes originally designated candidate division OP10. Int.

12. Mori K, Yamaguchi K, Sakiyama Y, Urabe T, Suzuki K: Caldisericum exile gen. nov., sp. nov., an anaerobic, thermophilic, filamentous bacterium of a novel 
bacterial phylum, Caldiserica phyl. nov., originally called the candidate phylum OP5, and description of Caldisericaceae fam. nov., Caldisericales ord. nov. and Caldisericia classis nov. Int J Syst Evol Microbiol 2009, 59:2894-2898.

13. Podosokorskaya OA, Kadnikov VV, Gavrilov SN, Mardanov AV, Merkel AY, Karnachuk OV, Ravin NV, Bonch-Osmolovskaya EA, Kublanov IV: Characterization of Melioribacter roseus gen. nov., sp. nov., a novel facultatively anaerobic thermophilic cellulolytic bacterium from the class Ignavibacteria, and a proposal of a novel bacterial phylum Ignavibacteriae. Environ Microbiol 2013, 15:1759-1771.

14. Quast C, Pruesse E, Yilmaz P, Gerken J, Schweer T, Yarza P, Peplies J, Glöckner FO: The SILVA ribosomal RNA gene database project: improved data processing and web-based tools. Nucl Acids Res 2013 41: D590-D596. Whitman, WB, Euzéby, J, Amann, R, Rosselló-Móra R: Uniting the classification of cultured and uncultured bacteria and archaea using 16S rRNA gene sequences. Nat Rev Microbiol 2014, 12:635-645.

- Although not focusing on thermophiles and focused only on Bacteria, this paper provides a great perspective on the yet-uncultivated microbial world. The authors use all taxa on the List of Prokaryotic Names with Standing in Nomenclature to calibrate 16S rRNA gene distance to the taxonomic structure and then use the calibration to expand the taxonomic structure to $16 \mathrm{~S}$ rRNA genes from cultivation-independent studies, generating estimates of biodiversity and an up-to-date view on 16S rRNA gene exploration.

16. Cole JK, Peacock JP, Dodsworth JA, Williams AJ, Thompson DB, Dong H, Wu G, Hedlund BP: Sediment microbial communities in Great Boiling Spring are controlled by temperature and distinct from water communities. ISME $J$ 2013, 7:718-729. 
- This study shows focuses on Great Boiling Spring, in the U.S. Great Basin, a hotspot for 'Aigarchaeota' diversity and abundance. This spring contains at least four genus-level groups of 'Aigarchaeota'. In the highest temperature sample, 'Aigarchaeota' comprise $>50 \%$ of $16 \mathrm{~S}$ rRNA gene pyrotags. Pyrotag-based estimates of 'Aigarchaeota' abundance in this spring are similar to metagenomic estimates (IMG \#2053563014)

17. Sharp CE, Brady AL, Sharp GH, Grasby SE, Stott MB, Dunfield PF: Humboldt's spa: microbial diversity is controlled by temperature in geothermal environments. ISME J 2014, 8:1166-1174.

- This study examines 16S rRNA gene pyrotag data from $\sim 170$ geothermal systems in Canada, New Zealand, United States, and China and shows a richness and diversity maximum at $\sim 24{ }^{\circ} \mathrm{C}$, with both measurements declining as temperature increases.

19. Baker BJ, Dick GJ: Omic Approaches in Microbial Ecology: Charting the Unknown. Microbe 2013, 8:353-360.

20. Kantor RS, Wrighton KC, Handley KM, Sharon I, Hug LA, Castelle CJ, Thomas BC, Banfield, JF: Small genomes and sparse metabolisms of sedimentassociated bacteria from four candidate phyla. mBio 2013, 4:e00708-00713.

18. Parte, A.C. LPSN-list of prokaryotic names with standing in nomenclature. Nucl. Acids Res 2014, 42:D613-D616.

22. Hamilton TL, Koonce E, Howells A, Havig JR, Jewell T, de la Torre JR, Peters JW, Boyd ES: Competition for ammonia influences the structure of 
chemotrophic communities in geothermal springs. Appl Environ Microbiol 2014, 80:653-661.

23. Hedlund BP, Dodsworth JA, Cole JK, Panosyan HH: An integrated study reveals diverse methanogens, Thaumarchaeota, and yet-uncultivated archaeal lineages in Armenian hot springs. Antonie Van Leeuwenhoek. 2013, 104:71-82.

24. Hou W, Wang S, Dong H, Jiang H, Briggs BR, Peacock JP, Huang Q, Huang L, Wu G, Zhi X, Li W, Dodsworth JA, Hedlund BP, Zhang C, Hartnett HE, Dijkstra P, Hungate BA: A comprehensive census of microbial diversity in hot springs of Tengchong, Yunnan Province China using 16S rRNA gene pyrosequencing. PLoS One 2013, 8:e53350.

25. Huang Q, Jiang H, Briggs BR, Wang S, Hou W, Li G, Wu G, Solis R, Arcilla CA, Abrajano T, Dong $\mathrm{H}$ : Archaeal and bacterial diversity in acidic to circumneutral hot springs in the Philippines. FEMS Microbiol Ecol 2013, 85:452-464.

26. Miller SR, Strong AL, Jones KL, Ungerer MC: Bar-coded pyrosequencing reveals shared bacterial community properties along the temperature gradients of two alkaline hot springs in Yellowstone National Park. Appl Environ Microbiol 2009, 75:4565-4572.

27. Wang S, Hou W, Dong H, Jiang H, Huang L, Wu G, Zhang C, Song Z, Zhang Y, Ren H, Zhang J, Zhang L: Control of temperature on microbial community structure in hot springs of the Tibetan Plateau. PLoS One 2013, 8:e62901.

28. Inskeep WP, Jay ZJ, Tringe SG, Herrgård MJ, Rusch DB; YNP Metagenome Project Steering Committee and Working Group Members: The YNP Metagenome Project: Environmental Parameters Responsible for Microbial 

4:67.

- This paper summarizes the Yellowstone National Park Metagenome Project, which included twenty sites, roughly divided into phototrophic mat communities, Aquificales-dominate "streamer" communities, and Archaea-dominated communities. Although not focused on major, yet-uncultivated groups, the YNP Metagenome Project is the largest coordinated effort to obtain metagenomes from thermal environments.

29. Markowitz VM, Chen IM, Chu K, Szeto E, Palaniappan K, Pillay M, Ratner A, Huang J, Pagani I, Tringe S, Huntemann M, Billis K, Varghese N, Tennessen K, Mavromatis K, Pati A, Ivanova NN, Kyrpides NC: IMG/M 4 version of the integrated metagenome comparative analysis system. Nucleic Acids Res 2014, 42:D568-573.

30. Konstantinidis KT, Tiedje JM: Prokaryotic taxonomy and phylogeny in the genomic era: advancements and challenges ahead. Curr Opin Microbiol 2007, 10:504-509.

31. Caporaso JG, Kuczynski J, Stombaugh J, Bittinger K, Bushman FD, Costello EK, Fierer N, Peña AG, Goodrich JK, Gordon JI, Huttley GA, Kelley ST, Knights D, Koenig JE, Ley RE, Lozupone CA, McDonald D, Muegge BD, Pirrung M, Reeder J, Sevinsky JR, Turnbaugh PJ, Walters WA, Widmann J, Yatsunenko T, Zaneveld J, Knight R: QIIME allows analysis of high-throughput community sequencing data. Nat Methods 2010, 7:335-336.

32. Schloss PD, Westcott SL, Ryabin T, Hall JR, Hartmann M, Hollister EB, Lesniewski RA, Oakley BB, Parks DH, Robinson CJ, Sahl JW, Stres B, Thallinger GG, Van Horn DJ, Weber CF: Introducing mothur: open-source, platform-independent, community-supported software for describing and 

7541. M, Kanai A, Atomi H, Takai K, Takami H: Insights into the evolution of Archaea and eukaryotic protein modifier systems revealed by the genome of a novel archaeal group. Nucleic Acids Res 2011, 39:3204-3223.

- This study describes a complete genomic assembly for the founding member of the 'Aigarchaeota', "Candidatus Caldiarchaeum subterraneum", from a subterranean gold mine in Japan. The paper describes possible metabolic features, including hydrogenotrophy, autotrophy, aerobic respiration, and nitrate reduction, as well as some eukaryotic features such as a possible ubiquitin protein modification system. W, Nunoura T, Itoh T, Hattori M, Takai K: A deeply branching thermophilic bacterium with an ancient acetyl-CoA pathway dominates a subsurface ecosystem. PLoS One 2012, 7:e30559.

- This paper describes a complete genomic assembly for the founding member of the 'Acetothermia' (OP1), "Candidatus Acetothermum autotrophicum", from a subterranean gold mine in Japan. This organism is likely to be an acetogen capable of autotrophy via the Wood-Ljungdahl pathway. The paper also speculates on the deep evolutionary origin of $\mathrm{H}_{2}$-dependent acetogenesis.

35. Kozubal MA, Romine M, Jennings Rd, Jay ZJ, Tringe SG, Rusch DB, Beam JP, McCue LA, Inskeep WP: Geoarchaeota: a new candidate phylum in the Archaea from high-temperature acidic iron mats in Yellowstone National Park. ISME J. 2013, 7:622-634.

- The 'Geoarchaeota' (NAG1) is described here as a candidate phylum of Archaea, represented by a composite metagenome assembled from One Hundred Springs Plain Spring in Yellowstone; however, this group is monophyletic with the Thermoprotei so the candidate phylum status is in question. 
36. Elkins JG, Kunin V, Anderson I, Barry K, Goltsman E, Lapidus A, Hedlund BP, Hugenholtz P, Kyrpides N, Graham D, Keller M, Wanner G, Richardson P,

- This study describes a complete genomic assembly for a member of the 'Korarchaeota', "Candidatus Korarchaeum thermofilum", from an enrichment from

523 Obsidian Pool, Yellowstone National Park.

37. Dodsworth JA, Blainey PC, Murugapiran SK, Swingley WD, Ross CA, Tringe SG, Chain PSG, Raymond J, Quake SR, and Hedlund BP: Single-cell and metagenomic analyses indicate a fermentative, saccharolytic lifestyle for members of the OP9 lineage. Nature Comm 2013, 4:1854.

- This study describes a synergistic analysis of single-cell genomics data and metagenomics data, leading to the assembly of nearly complete genomes for two different species of 'Atribacteria' (OP9) inhabiting different springs in the U.S. Great Basin. Genomic data and in situ enrichment on lignocellulose indicate a strictly fermentative, saccharolytic lifestyle.

38. Rinke C, Schwientek P, Sczyrba A, Ivanova NN, Anderson IJ, Cheng JF, Darling A, Malfatti S, Swan BK, Gies EA, Dodsworth JA, Hedlund BP, Tsiamis G, Sievert SM, Liu WT, Eisen JA, Hallam SJ, Kyrpides NC, Stepanauskas R, Rubin EM, Hugenholtz $\mathrm{P}$, Woyke T, Insights into the phylogeny and coding potential of microbial dark matter. 2013, Nature 499:431-437. 
39. Beam JP, Jay ZJ, Kozubal MA, Inskeep WP. Niche specialization of novel Thaumarchaeota to oxic and hypoxic acidic geothermal springs of Yellowstone National Park. ISME J 2014, 8:938-951.

40. Garcia Costas AM, Liu Z, Tomsho LP, Schuster SC, Ward DM, Bryant DA:

41. Sutcliffe IC: Cell envelope architecture in the Chloroflexi: a shifting frontline in a phylogenetic turf war. Environ Microbiol 2011, 13:279-282.

42. Junglas B, Briegel A, Burghardt T, Walther P, Wirth R, Huber H, Rachel R: Ignicoccus hospitalis and Nanoarchaeum equitans: ultrastructure, cell-cell interaction, and 3D reconstruction from serial sections of freeze-substituted cells and by electron cryotomography. Arch Microbiol 2008, 190:395-408.

43. Baker BJ, Comolli LR, Dick GJ, Hauser LJ, Hyatt D, Dill BD, Land ML,

44. Castelle CJ, Wrighton KC, Thomas BC, Hug LA, Brown CT, Wilkins MJ, Frischkorn KR, Tringe SG, Singh A, Markillie LM, Taylor RC, Williams KH, Banfield JF: Genomic expansion of domain Archaea highlights roles for organisms from new phyla in anaerobic carbon cycling. Curr Biol 2015, doi: 10.1016/j.cub.2015.01.014.

45. Ghai R, Pašić, Fernández AB, Martin-Cuadrado AB, Mizuno CM, McMahon KD, Papke RT, Stepanauskas R, Rodriguez-Brito B, Rohwer F, Sánchez-Porro C, Ventosa A, Rodríguez-Valera F: New abundant microbial groups in aquatic hypersaline environments. Sci Rep 2011, 1:135. 
46. He X, McLean JS, Edlund A, Yooseph S, Hall AP, Liu SY, Dorrestein PC, Esquenazi E, Hunter RC, Cheng G, Nelson KE, Lux R, Shi W: Cultivation of a human-associated TM7 phylotype reveals a reduced genome and epibiotic parasitic lifestyle. Proc Natl Acad Sci U S A 2015, 112:244-249.

47. Huber H, Hohn MJ, Rachel R, Fuchs T, Wimmer VC, Stetter KO: A new phylum of Archaea represented by a nanosized hyperthermophilic symbiont. Nature 2002, 417:63-67.

48. Narasingarao P, Podell S, Ugalde JA, Brochier-Armanet C, Emerson JB, Brocks JJ, Heidelberg KB, Banfield JF, Allen EE: De novo metagenomic assembly reveals abundant novel major lineage of Archaea in hypersaline microbial communities. ISME J 2012, 6:81-93.

49. Podar M, Makarova KS, Graham DE, Wolf YI, Koonin EV, Reysenbach AL. Insights into archaeal evolution and symbiosis from the genomes of a nanoarchaeon and its inferred crenarchaeal host from Obsidian Pool, Yellowstone National Park. Biol Direct 2013, 8:9. Archaea: one hundred genomes later. Curr Opin Microbiol 2011, 14:274-281.

- - This review describes the landscape of archaeal genomics, including a summary of genes predicted to encode various components of cell division, DNA maintenance, protein ubiquitinylation, and transcription systems, including systems in 'Aigarchaeota', 'Korarchaeota', and 'Nanoarchaeota'. The paper also presents a cogent discussion of archaeal phylogeny and taxonomy from a phylogenetic and genomic perspective.

51. Gribaldo S, Brochier-Armanet C: Time for order in microbial systematics. Trends Microbiol 2012, 20:209-210. 
52. Guy L, Ettema TJ: The archaeal 'TACK' superphylum and the origin of eukaryotes. Trends Microbiol 2011, 19: 580-587.

53. Guy L, Spang A, Saw JH, Ettema TJ: 'Geoarchaeote NAG1' is a deeply rooting lineage of the archaeal order Thermoproteales rather than a new phylum. ISME J 2014, 8:1353-1357.

54. Sutcliffe, I.C., Trujillo, M.E., Whitman, W.B., Goodfellow, M: A call to action for the international committee on systematics of prokaryotes. Trends Microbiol 2013, 21:51-52.

55. Konstantinidis KT, Rosselló-Móra R: Classifying the uncultivated microbial majority: A place for metagenomic data in the Candidatus proposal. Syst Appl Microbiol 2015, doi: 10.1016/j.syapm.2015.01.001.

56. Hedlund BP, Dodsworth JA, Staley JT: The changing landscape of microbial biodiversity exploration and its implications for systematics. Syst Appl Microbiol 2015, in review.

57. Anderson RE, Sogin ML, Baross JA: Evolutionary strategies of viruses, bacteria and archaea in hydrothermal vent ecosystems revealed through metagenomics. PLoS One. 2014, 9:e109696.

58. Inskeep WP, Rusch DB, Jay ZJ, Herrgard MJ, Kozubal MA, Richardson TH, Macur RE, Hamamura N, Jennings Rd, Fouke BW, Reysenbach AL, Roberto F, Young M, Schwartz A, Boyd ES, Badger JH, Mathur EJ, Ortmann AC, Bateson M, Geesey G, Frazier M: Metagenomes from high-temperature chemotrophic systems reveal geochemical controls on microbial community structure and function. PLoS One 2010, 5:e9773. 
59. Nakai R, Abe T, Takeyama H, Naganuma T: Metagenomic analysis of 0.2- $\boldsymbol{\mu m}$ passable microorganisms in deep-sea hydrothermal fluid. Mar Biotechnol (NY) 2011, 13:900-908.

60. Xie W, Wang F, Guo L, Chen Z, Sievert SM, Meng J, Huang G, Li Y, Yan Q, Wu $\mathrm{S}$, Wang $\mathrm{X}$, Chen S, He G, Xiao X, Xu A: Comparative metagenomics of microbial communities inhabiting deep-sea hydrothermal vent chimneys with contrasting chemistries. ISME J 2011, 5:414-426.

61. Vignais PM: Hydrogenases and $\mathbf{H}(+)$-reduction in primary energy conservation. Results Probl Cell Differ 2008, 45:223-252.

63. Wolf YI, Makarova KS, Yutin N, Koonin EV: Updated clusters of orthologous genes for Archaea: a complex ancestor of the Archaea and the byways of horizontal gene transfer. Biol Direct 2012, 14:46.

62. Petitjean C, Deschamps P, López-García P, Moreira D, Brochier-Armanet C: Extending the conserved phylogenetic core of Archaea disentangles the evolution of the third domain of Life. Mol Biol Evol 2015, doi: 10.1093/molbev/msv015.

64. Raymann K, Forterre P, Brochier-Armanet C, Gribaldo S: Global phylogenomic analysis disentangles the complex evolutionary history of DNA replication in archaea. Genome Biol Evol 2014, 6:192-212.

65. Kimura H, Sugihara M, Kato K, Hanada S: Selective phylogenetic analysis targeted at 16S rRNA genes of thermophiles and hyperthermophiles in deepsubsurface geothermal environments. Appl Environ Microbiol 2006 ,72:21-27. 
66. Costa KC, Navarro JB, Shock EL, Zhang CL, Soukup D, Hedlund BP: Microbiology and geochemistry of great boiling and mud hot springs in the United States Great Basin. Extremophiles 2009, 13:447-459.

67. Dodsworth JA and Hedlund BP: Microbiology and geochemistry of Smith Creek and Grass Valley hot springs: Emerging evidence for wide distribution of novel thermophilic lineages in the US Great Basin. J Earth Sci 2010, 21:315-318.

68. Vick TJ, Dodsworth JA, Costa KC, Shock EL, Hedlund BP: Microbiology and geochemistry of Little Hot Creek, a hot spring environment in the Long Valley Caldera. Geobiology 2010, 8:140-154.

69. Blank CE, Cady SL, Pace NR. Microbial composition of near-boiling silicadepositing thermal springs throughout Yellowstone National Park: Appl Environ Microbiol 2002, 68:5123-5135.

70. Stamatakis A: RAxML version 8: a tool for phylogenetic analysis and postanalysis of large phylogenies. Bioinformatics 2014, 30:1312-1313. 
688 Figure 1. Summary of unclassified reads in 16S rRNA gene amplicon datasets. Raw 16S 689 rRNA gene pyrotags or Illumina tags from $[\bullet 16, \bullet 17,21-27]$ were processed using Qiime 690 [31] and mothur [32], respectively, using default parameters (97\% OTU clustering) and 691 identified using the Greengenes taxonomy, accounting for unclassified classes, orders, 692 and families. Phyla were not plotted due to uncertainty about archaeal phylum-level 693 taxonomy. $n$ represents the number of rRNA gene tag datasets per each site. Violin plots 694 depict the range and data model (colored area), $25^{\text {th }}$ and $75^{\text {th }}$ percentile (box), mean (dark 695 bar), and median (light bar). Individual data points are statistical outliers. Data are 696 detailed in Table S1. Newly published data from the Great Basin were submitted to the 697 NCBI under SRA\# XXXXXX.

699 Figure 2. Phenotypic characteristics and fragment recruitment-based prevalence of yet700 uncultivated thermophiles. (A) Genomic anchoring. Characteristics were either directly

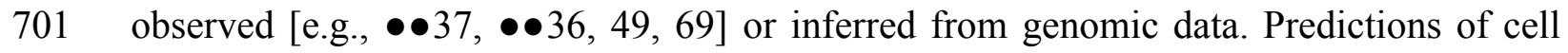
702 shape (MreB or crenactin) or membrane structure (e.g., BamA/YaeT, OmpH, TolC, 703 TonB, secretin [41]) were predicted using BLAST $\left(<1 \mathrm{e}^{-10}\right)$. (B) Genomic anchoring.

704 Reads were recruited from 68 metagenomic datasets from geothermal sites [•28, 57-60], 705 using a >100 bp, 70\% nucleic acid identity cutoff using seven thermophile genomes

$706[\bullet \bullet 37, \bullet \bullet 36,49, \bullet \bullet 38, \bullet \bullet 34]$. The figure summarizes data from the ten metagenomic 707 datasets with the highest apparent abundance of the target groups; data for the additional 708 metagenomes are shown in Table S3. 
710 Figure 3. Phylogenetic diversity of 'Aigarchaeota' lineages. 16S rRNA gene sequences

711 with BLASTN identity $>80 \%$ to " $\mathrm{Ca}$. Caldiarchaeum subterraneum" were mined from

712 GenBank, along with sequences from single-cell genomes and metagenomes in IMG-M

713 [29]. Potential 'Aigarchaeota' $16 \mathrm{~S}$ rRNA gene sequences $>1,200$ nucleotides $(n=82$; Table

714 S4) were aligned against the SILVA reference alignment in mothur, hard filtered using

715 Lane mask, soft filtered (positions with $>50 \%$ gaps), and processed in RAxML with

7161,000 pseudoreplicates $[14,32,70]$. The resulting phylogenetic tree was delineated into

717 nine genus-level groups (G1-G9) according to $>95 \%$ nucleotide identity $[\bullet \bullet 15]$. Taxon

718 jackknifing was performed by randomly removing $30 \%$ of the sequences (10X) and

719 repeating the bootstrapping analysis (Table S6), further supporting the monophyly of all

720 groups. A similar phylogenetic analysis with the Lane mask but without a soft filter

721 yielded similar results.

722

723 Figure 4. Distribution of 'Aigarchaeota' based on 16S rRNA gene sequences. (A)

724 Geographic distribution of 'Aigarchaeota' genus-level groups, including short sequences

$725(<1,200 \mathrm{bp})$ in GenBank that could be confidently mapped to groups (Table S4). (B)

726 Environments in which 'Aigarchaeota' groups are found. Colors correspond to genus-

727 level groups in Figure 3; open dots are not confidently placed in a genus-level group. 
Yellowstone $(n=71)$

31.2-88.4 ${ }^{\circ} \mathrm{C}$; pH 2.1-9.6

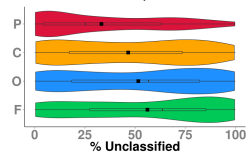

Western Canada $(n=77)$ 31.3-85.9 ${ }^{\circ} \mathrm{C}$; pH 6.4-8.6
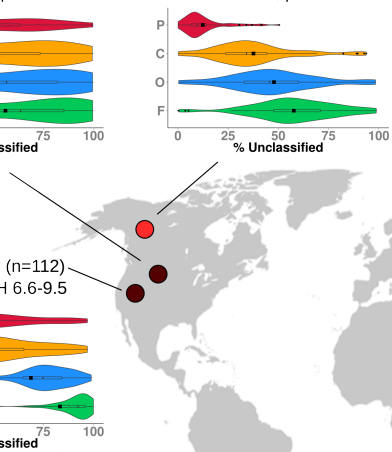

Great Basin $(n=112)$ 31-95 ${ }^{\circ} \mathrm{C}$; pH 6.6-9.5

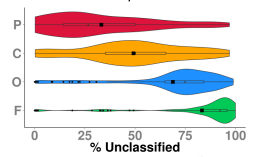

Percent unclassified at class level
10-20
P: Phylum
20-30
$30-40$
$>40$

Armenia $(n=2)$

44-53 ${ }^{\circ} \mathrm{C}$; pH 7.2-7.5

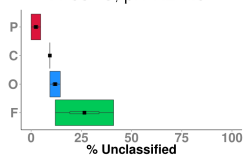

Tibet $(n=15)$

$37-97^{\circ} \mathrm{C} ; \mathrm{pH} 6-9.5$

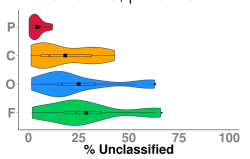

Tengchong $(n=43)$

55-93 ${ }^{\circ} \mathrm{C}$; $\mathrm{pH} 2.5-9.4$

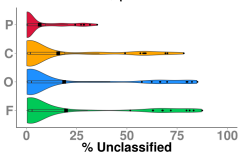

Philippines $(n=6)$ 60-92 ${ }^{\circ} \mathrm{C}$; $\mathrm{pH} 3.7-6.6$

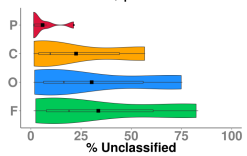

New Zealand $(n=46)$ 31.4-94.7 ${ }^{\circ} \mathrm{C}$; pH 2.1-8.9

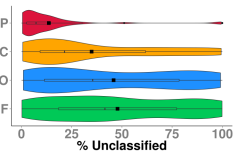




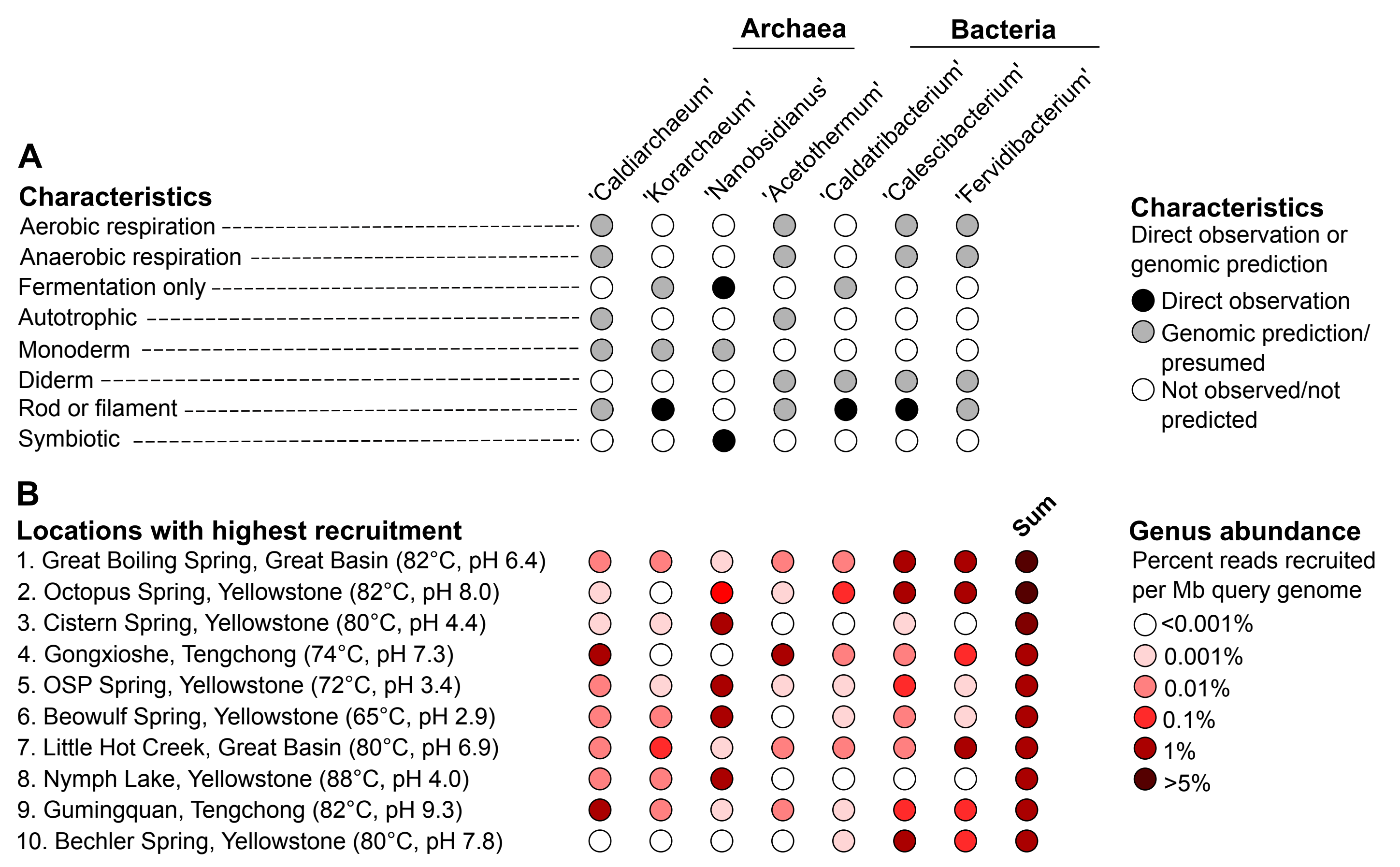




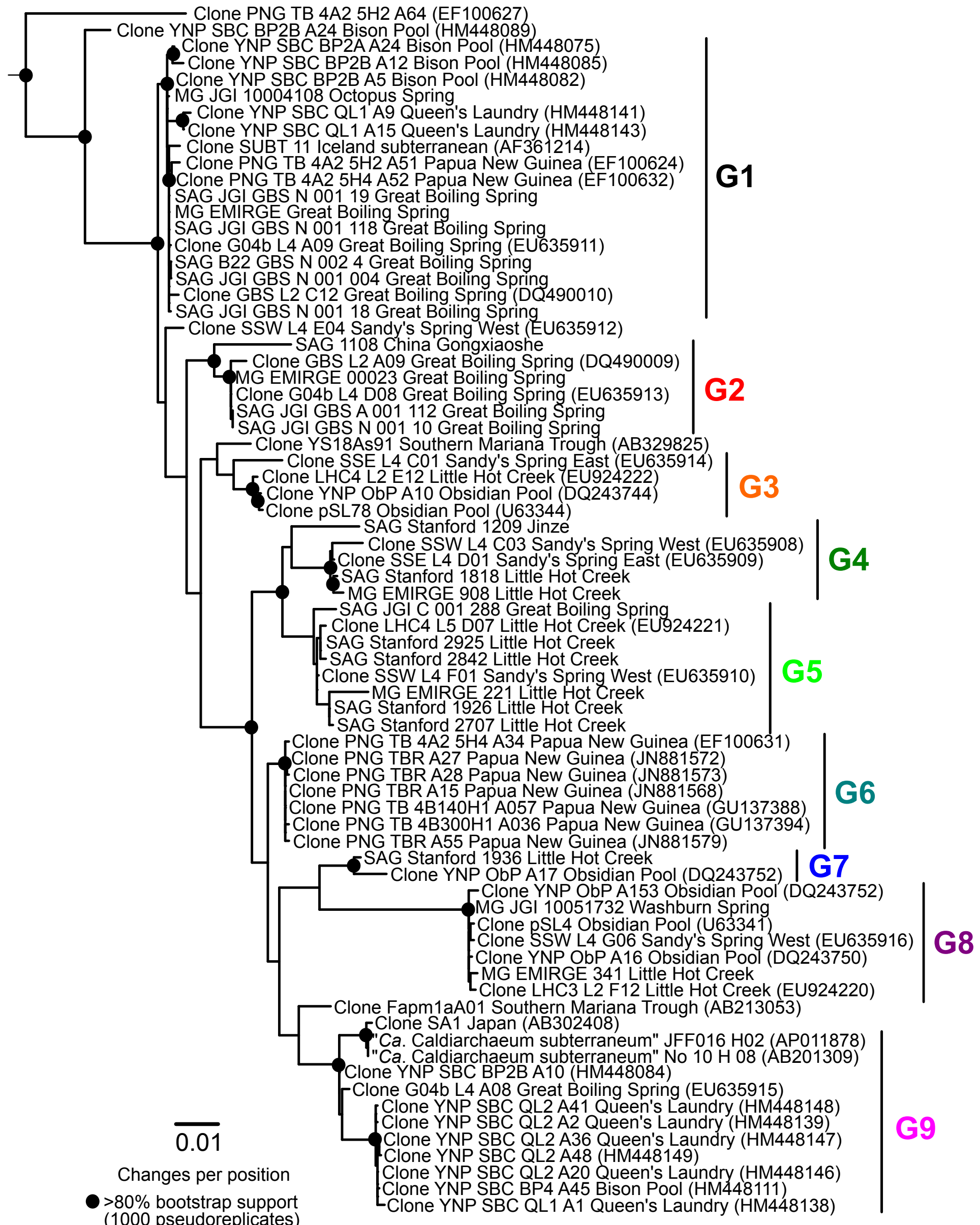




\section{Yellowstone}

Bechler •

Bison Pool $\bullet \bullet \circ$

Boulder Spring ••

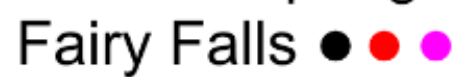
Heart Lake $\bullet \bullet \bullet$

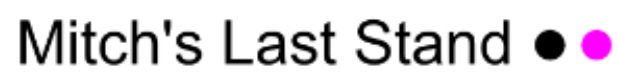

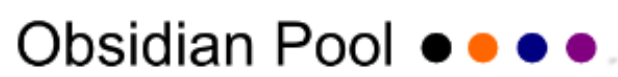
Octopus Spring Perpetual Spouter • Queen's Laundry •• Washburn •

\section{Great Basin}

Grass Valley Spring Great Boiling Spring

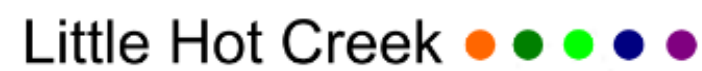

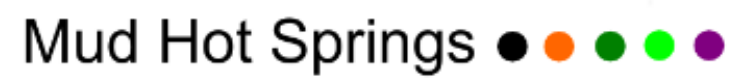
Nevada National Security Site $\bullet \bullet \bullet$

\section{Japan}

Gold Mine •

Nakabusa Hot Spring • $\bullet$ Toyoha Mine • Nagasaki • Yunohama •

\section{Tengchong}

Gongxiaoshe •• Jinze • • • Tengchong $\bullet \bullet \bullet$ 